This is the first article in a new quarterly series called "Voices of the Future of Medicine," which highlights exemplary reflective essays by second-year medical students on their experience of conducting an ethnographic interview with a patient from an ethnic or cultural background other than their own. Dr William Toffler provides the context.

\title{
Ethnographic Studies in the Principles of Clinical Medicine
}

By William L Toffler, MD

Oregon Health and Sciences University (OHSU) introduced the Principles of Clinical Medicine (PCM) course in 1992 with the intent of providing medical students early in their training with a patient-centered care context. Students are enrolled in this two-year, longitudinal course at the same time they are learning basic sciences. PCM consists of two components: a weekly preceptorship in which students spend four hours a week with a community physician and four hours in classes focusing on the knowledge, skills, and attitudes involved in providing patient-centered care. Classes are taught with largegroup presentations followed by small-group discussions, and include an introduction to patient examination and diagnostic reasoning as well as to key patient-care issues drawn from epidemiology, medical ethics, organization of health care systems, and the behavioral and social sciences. We believe this curriculum better prepares our students for their third-year required rotations, as well as for their relationship with patients throughout their medical career.

One of the goals of this curriculum is to help students develop cultural sensitivity. This is not an easy task. Some students come to medical school feeling that they are openminded about other cultures; there-

\section{A Fundamental Prejudice}

By Ann Cooley

\section{The Ethnographic Interview The Presenting Situation}

Jane Doe is a 33-year-old Caucasian female who was born in a small farming community. She came into clinic on her own to discuss continued irregularity of her menstrual periods after the birth of her last child. An interview was conducted prior to examination as part of a routine new patient history. Mrs Doe sat crosslegged on the exam table throughout the interview. She also fidgeted with her necklace constantly.

My preceptor felt that Mrs Doe's failure to return to a regular menstrual cycle nine months after the birth of her last child was still within the normal range especially since she was still nursing. Further questioning revealed that this was Mrs Doe's tenth child, and she was only concerned because she had returned to a normal cycle at this point after delivering her previous children. She did admit to gaining quite a bit of weight with this pregnancy due to additional stressors in her life at the time, and her BMI was $32 \mathrm{~kg} / \mathrm{m}^{2}$ at the time of the visit. The importance of weight loss and exercise was discussed, but Mrs Doe expressed doubts as to whether she'd be able to accomplish this while trying to look after her ten children, none of whom attend any formal schooling outside of the home.

\section{The Informant}

Mrs Doe moved away from home after marrying her husband upon turning 16. She stated they moved to escape the corruptive influence of her parents. She noted that her parents had only allowed the marriage because she had been pregnant with her first child at the time. She had only completed school through the eighth grade, and had dropped out at that time because of the encouragement of her future husband.

Although she was born into a mildly religious family, Mrs Doe had felt drawn to a different kind of religion when she was young. She described her faith as "a
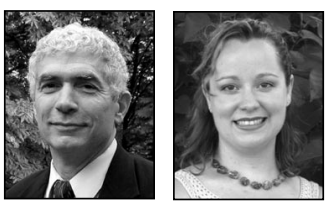

William L Toffler, MD, (left) is a professor and the Director of Predoctoral Education in the Department of Family Medicine at Oregon Health and Science University (OHSU). Ann Cooley, (right) is a third-year medical student at Oregon Health and Science University (OHSU). She received her Bachelor's Degree in Theater Arts from Portland State University in 2000. E-mail: rivinusa@ohsu.edu. 
(continued from previous page)

fore they are culturally competent. Nevertheless, we wish all students develop the kind of knowledge of and experience with other cultures that they will need as physicians. To do this we must walk a fine line between teaching salient characteristics of various cultures, which students dismiss as "stereotyping," and giving them vague advice about the importance of treating all patients with equal respect and trying to understand their worldviews.

Another goal is to develop students' ability to reflect thoughtfully upon key issues affecting their future practice of medicine. Students engage in group discussions with their peers and physician group leaders; they also are required to write a quarterly essay. Essay assignments vary in structure and content.
Specific requirements have evolved over the years along with the curriculum but the overall goal of encouraging self-reflective thinking and writing remains unchanged.

In 2001, we attended a national meeting of the Society of Teachers of Family Medicine at which we were inspired by the work of Dorothy Mull, $\mathrm{PhD}$, a medical anthropologist at Keck School of Medicine at University of Southern California. Dr Mull taught students more about the patients they were seeing from the Los Angeles Latino community by assigning them an "ethnographic interview." With her assistance, each student found a patient from the Latino community, arranged for a home visit, and interviewed the patient with the assistance of a list of specific questions she had prepared for them.
As we all know, we never learn as well from books as we do from lived experience and this method of introducing students to patients with lives and worldviews very different from their own was innovative and intriguing. We wondered if it would work in Portland, where ethnic communities are far less defined and where few students work with preceptors that see ethnically diverse patient populations.

With Dr Mull's permission, we adapted the assignment. At first, we framed the assignment as an opportunity for students to interview a patient who would be considered "underserved." We also asked for more personal reflection on the experience-that is, to relate their individual patient's situation to what they have learned during the PCM quarter devoted to discussion of US health care policy and economics. Some students did interview patients of different cultures and ethnicities and their experiences greatly impressed the small-group leaders who read the essays on the basis of their experiences. However, finding a patient was difficult for some students and they opted to interview friends or next door neighbors, who are "underserved" simply because they had no health insurance. Although this could be a valuable learning experience, it did not meet the goal of increasing students' cultural sensitivity. So last year, we rethought the assignment and reworded it to specifically ask that students interview a patient "from an ethnic or cultural background other than your own."

(continued on next page) calling," but refused to name any organized religion to which she subscribed. She first met her husband at a local church gathering when she was 12; she noted that they were married "in the eyes of the lord" when she was 14 . She has since had ten children and three miscarriages, and continues to refuse to use any form of birth control. Questioning revealed that her husband controlled all aspects of the family's daily life from what they were to wear, to where they could go, and with whom they could interact. Her main support came from the other members of her church.

\section{Household Composition}

Mrs Doe reported that she is now the sole provider in the house because her husband had been recently convicted of child abuse relating to his religious practices. After a long struggle with Child Protective Services (CPS), Mrs Doe was allowed to retain custody of her children, and has not been to visit her husband since his incarceration. She lives in a three-bedroom house about 20 minutes outside of town with her ten children who range from aged 16 years to 9 months. Review of the medical records revealed that a CPS worker continues to make home visits several times each month.
The family distributes itself fairly evenly amongst the bedrooms with the four older boys sharing one bedroom, the four older girls in another, and the two youngest sleeping in their mother's room. Mrs Doe did express some concern over finding enough space for all the children as they continued to grow older. She also related a great deal of trepidation for the time when her husband returns from prison as things were beginning to change in his absence.

\section{Material Possessions, Transport, and Family Support}

Questioning revealed that the slightly more rural location of the family home proved to make certain tasks quite difficult. They did not own a car, and before the last six months there was no phone in the house. When she needs to go to town, Mrs Doe walks about five minutes to a neighbor's house, and they travel together. The entire community belongs to the same church, and this serves as a vital support network for the family. Mrs Doe even made mention of the church owning part of the house she lived in, but this was not elaborated on with further questioning.

The family also has no TV or radio, and receives no outside communication like newspapers or magazines. 
(continued from previous page)

Because this assignment involved sending medical students out into the community, we initially had to obtain permission from OHSU legal affairs and the School of Medicine. The activity was approved, provided we added a requirement to the assignment that students obtain written permission from patients to be interviewed, advised students who arranged home visits not to go alone, and reminded students that in visiting homes as health care professionals they were required to report any suspicions of child abuse. These guidelines seemed sensible for any home visit, no matter what the socioeconomic or ethnic status of a patient. Nonetheless, some students perceived these precautions as cul- turally insensitive with an implicit assumption that patients of other cultures are more dangerous or more prone to domestic violence.

Sometimes students teach their faculty as much as we teach them! Their concerns have been heard. Appropriate revisions to the wording of the assignment are complete and we will strive to communicate these changes more effectively to next year's students.

That said, most of our students in this and past years have responded quite favorably to this assignment, acknowledging that it can be among the most valuable and memorable experiences of their first two years. It moves them out of their comfort zone and enables them to learn things about patients and cultures that they never would otherwise. We consider it to be the best opportunity we offer to promote the practice of culturally sensitive medicine. Our faculty continue to be amazed not only that students learn so much, but that they often write so eloquently about these experiences.

When I matriculated in medical school more than three decades ago, no time was devoted to these important issues. Our medical school curriculum has been revised to address many of these shortcomings. The insights, capacity for self-disclosure, and openness to growth reflected in these essays by secondyear students suggest that our efforts have been worthwhile. These
"Voices of the Future of Medicine" give me great hope and confidence-hope for the future of our profession and confidence in the exceptional quality of care these future physicians will ultimately provide their patients.

I am grateful to Dr Janisse for suggesting and making it possible to publish some of our most-talented students' writings in The Permanente Journal, and to the Collegium for the Study of the Spirit of Medicine, a group within The Foundation for Medical Excellence (TFME), a Portland, OR organization, for recognizing the worth of this experience and for developing a scholarship program in 2007. This truly exemplifies the spirit of medicine.
All of the children's educational materials are provided by the church, and taught by Mrs Doe and until recently her husband. Additional familial support is absent because Mrs Doe has not spoken to her biological family since she left home at 16 . Her husband strongly disapproved of her family's way of life, but she did admit that she has been tempted to call her mother since her husband has been in jail. The CPS worker she had been working with had encouraged her to do this.

\section{Family Work and Income}

Prior to Mr Doe's arrest, he modestly supported the family through employment. Mrs Doe related that he worked overtime so the family could afford some extras occasionally. At the time of the interview, however, no one was working outside of the home, and the family was being supported entirely by state assistance and the generosity of fellow members of the church. Mrs Doe tries to supplement this by taking in sewing projects, but she is having a hard time keeping up with the work while still trying to care for ten children. She mentioned that her eldest had offered to get a job, but she didn't like the idea of her kids supporting the family. At this point in the interview she brought up the idea of attempting to change her situation by perhaps heading back to live with her parents, but she wasn't sure if that would even be an option after not speaking to them for so long.

\section{Housing Costs}

This was not covered in the interview past the reference to the church owning part of the house the family occupied.

\section{Medicines and Herbs in the Home}

No medications were allowed in the home, and healing was provided mainly in the form of prayer. Specific herbal remedies were not discussed.

\section{Folk Medical Beliefs and Practices}

Up until recently, Mrs Doe's husband had forbid members of the family from accessing traditional allopathic medical care. Because the family relies so heavily on faith for healing, most medical problems are treated by attending a prayer service for the afflicted individual. Members of the church gather together, sometimes for days, and pray for health and recovery. Mrs Doe did relate that her husband's views were quite extreme even within their church. Many other members sought out care from allopathic providers in addition to turning to faith for healing. She had also received prenatal care during each of her pregnancies even though she would only begin coming to the doctor in her third trimester. All of the children had also been to the doc- 
tor at one point or another, she said mainly to keep CPS off of their back. When asked why she had decided to come in on that day, Mrs Doe commented that since her husband had been in jail she had started wearing pants and had cut her hair, so why not see what the doctor had to say about what was going on with her body. Other members of her church had been encouraging her in some of these changes.

\section{Health Problems in the Family}

Mrs Doe reported that she was "healthy as a horse," aside from the fact that her periods weren't regular yet. She also said that the children were doing quite well. Specific health issues were not discussed. She was, however, open to the suggestion of bringing the children in for a checkup some time in the future.

\section{Health Hazards in and Around the Home}

As the entire interview was conducted in the clinic, the home was only described. It can be surmised, however, that the greatest health hazard around the home is lack of supervision. Mrs Doe admitted that she has a hard time keeping track of all the children throughout the day, and that she occasionally has to leave them home alone while she runs errands. The older children watch the younger ones; however, the house is located on a busy county road and there have been times when one of the younger children has been found playing out by the street. The CPS worker has tried to address this concern and adequate childcare is one of the conditions of Mrs Doe retaining custody.

The other main concern addressed in the interview was the uncertainty of Mr Doe's response to some of the household changes that have taken place while he's been in jail. He won't be released for three years, but there was discussion throughout the interview about developing a plan for dealing with this eventuality.

\section{Risk Factors for Inadequate Health Care}

From the information obtained during this interview, it seems that the main risk factors for inadequate health care for this family are their lack of transport, their rural location and consequent isolation, the huge responsibility of caring for this family that is now sitting on the shoulders of one woman, and the impending return of a controlling patriarch. Mrs Doe has taken many steps toward improving her family's access to health care, but the biggest obstacle remains the desire and community support to seek out the care that is necessary.

\section{My Personal Reflection on This Interview}

Mrs Doe was one of the first patients at my preceptorship with whom I performed a complete history and physical; that was one of the things that made her very memorable. However, I noticed something else even as I conducted the interview that made our encounter remain so vivid in my memory. Even now as I sit at my desk writing this, I can feel the knot in my stomach that I first experienced sitting with her in the exam room that day. I enjoy getting involved in the lives of my patients - my interest in people was one of the main reasons I decided to become a doctor-but something about my reaction to Mrs Doe disturbed me. My very visceral response to her history stemmed from something that I hadn't yet encountered in the clinic. I disapproved of the choices she had made with her life. I didn't understand them and, even though I tried to sit back and listen objectively, I found that I was judging her as she told her story. I've always tried to put my opinions aside when working with other people. I make every attempt to focus on a common goal and work around disagreements that we may have in our personal ways of viewing the world. There was something different about my encounter with Mrs Doe, however, and I've spent a lot of time since that day trying to sort that part out.

I think one of the main differences lies in the very framework of the doctor-patient encounter. As physicians we take for granted that our patients walk into our offices every day and openly relate personal information they may not share even with those closest to them. Mrs Doe had never met me but she told me bits of her personal life as if I were an old friend. It made my response to ber lifestyle even more difficult for me to take. She trusted me to take the information she was telling me and then to make decisions with her best interests at heart. It was an unspoken contract between us and one that I cherished. I just hadn't thought about how my personal beliefs might come to affect it. Then as we confronted the idea of access to care this term in Principles of Clinical Medicine, I started to think about a different side of access. We've spent a lot of time over the past few weeks exploring access on a systems level, but what about access on a more personal level? The truth is that access to good medical care goes beyond the system right into the exam room where two people work together to resolve their differences and achieve a common goal. I've found myself wondering if it's possible to provide the same level of care when you disagree so strongly with how your patient chooses to live his or her life?

One of the interesting things that I've realized from this exploration is that I probably would have felt differently about Mrs Doe's situation had she not been so similar to me. I've seen a lot of Russian Orthodox women in clinic who lead lives with many similarities to Mrs Doe's but I haven't felt the same sense of disapproval when I've interviewed them. I view their lifestyle as stemming from the cultural background into which they

(continued on next page) 
were born, rather than from a lifestyle they chose to adopt. With Mrs Doe things were different. She grew up just a few miles from where I had. Her family sounded very familiar to me, yet she had ended up in such a different place: I chose to pursue an education, a career, and science; she chose to pursue a family and faith. I wondered how we could find common ground in the clinic when we come from such vastly different places-and is that even necessary to provide her with care?

I know a lot of physicians who would say that it's not. They feel quality care can be provided no matter how you feel about someone's beliefs or lifestyle. I'd like to think they were right. I also think that most physicians feel about medicine the way a lot of people feel about religion. We believe in it. There are basic tenants that we feel go without saying: The first is that everyone wants the same kind of care, or at least that everyone wants the best care available. After all, we have the evidence, scientific trials, and systematic reviews of the literature. What could be better than that? It turns out that there's something else assumed in that contract between patient and physician; and it's that the physician knows what is best when it comes to bealth care. That was really the thing that ultimately bothered me about my time with Mrs Doe. I kept wondering how she could raise her children and not bring them to be seen when they were sick. I believe in the healing power of things outside of medicine, but I also believe that there are times when it's safer with science. I wanted to ask ber how she could not provide ber children access to modern medicine, or at least medications, when they were sick but it was not the time or the place.

All of this has led me to an entirely different way of thinking about access to care. Perhaps to truly make care accessible to all of our patients we have to recognize some of our own limitations, and bow they affect how we, as providers, view our patients. Can I really keep my assumed contract with Mrs Doe-that I'll make the bealth care decisions that are in her best interest-if I'm constantly second guessing the personal choices she makes in caring for herself and her family? A simpler way to look at this is to think of a patient who smokes, or who is morbidly obese. What assumptions do I make about that person when I walk into the exam room? Do I provide that person with the same access to care I do others? I doubt that those patients always receive the same preventive care as their bealthier counterparts. Yet, we don't like to think of access in that way. As providers we prefer to take every opportunity to point the finger at something or some- one else. The bealth care system is broken. Drug companies charge too much for medication. I get reimbursed to spend no more than 15 minutes with a patient and that is just not enough time to do my job well. When are we going to turn the tide on ourselves? When are we going to look in the mirror and admit that even if we lived in the world of a perfect single-payer health care system, there would still be a problem with access to care? Until we learn to admit our own fallibility, and face the judgments that we make about our patients, we're never going to improve upon that problem.

I'm not a systems person. I don't see my life in the policy sphere, so I prefer instead to contemplate these more personal issues when it comes to global problems. I think we can improve patient access to bealth care by how we approach every office visit. I need to realize that when I encounter another Mrs Doe I will bring a certain amount of prejudice to that encounter. I'll do the same thing when I interview the patient with advanced COPD who just won't quit smoking or the obese patient who, despite all my efforts, just can't seem to lose weight. I'll bring in a sense of knowing what I think best and I might even have the science to back it up. And although sometimes I'll find empathy for those who can't or won't follow the path I've set for them, a lot of the time I won't. It's not something anyone wants to admit, but it is the truth and I learned it without even asking the day I interviewed Mrs Doe.

I've always prided myself on being nonjudgmental. That is one of the reasons this process of reflection hit me so hard. Health care is a personal business and, although the system may play a role in getting someone in the door, it's what happens once s/he is in the office that has the biggest impact. I think I could provide Mrs Doe with good quality care should she be my patient in the future. I don't think, however, that I could provide her with the same kind of care she'd receive from someone who could truly empathize with her beliefs. Our patients need us to be able to look beyond our own views to see what is in their best interest. Unfortunately, our views aren't like a fence you can peak through to see the other side. Ourviews are more like a lens that colors what we see no matter where we look. The only hope we have of moving beyond that limitation is taking the time to learn what color our lens is so we can always keep in mind how it's coloring our world. The process of interviewing Mrs Doe brought me closer to discovering how my own beliefs shape my encounters with patients. I bope to take away from this experience the tools to continue to develop this awareness throughout my career. 